\title{
PROLINE APPLICATION ENHANCES GROWTH OF CHILLI BY IMPROVING PHYSIOLOGICAL AND BIOCHEMICAL ATTRIBUTES UNDER SALT STRESS
}

\author{
Madiha Butt ${ }^{1, *}$, C.M. Ayyub ${ }^{1}$, M. Amjad ${ }^{1}$ and Rashid Ahmad ${ }^{2}$ \\ ${ }^{1}$ Institute of Horticultural Sciences, University of Agriculture, Faisalabad-38040, Pakistan; ${ }^{2}$ Department of \\ Agronomy, University of Agriculture, Faisalabad-38040, Pakistan. \\ "Corresponding author's e-mail: madeha_98@yahoo.com
}

\begin{abstract}
Salinity is a serious threat to crop production in Pakistan and all over the world. It imposes severe reduction in horticultural crop yield and production. Proline is reported to involve in salt tolerance in various crops. It was hypothesized that proline could ameliorate the salinity induced damages in physio-chemical attributes against salt stress. Therefore, a pot experiment was conducted to assess the role of foliar application of proline to improve the salt tolerance in chilli genotypes. Two chilli genotypes namely; Plahi and A-120 were grown under $50 \mathrm{mM} \mathrm{NaCl}$ saline condition. Various concentrations of proline $(0.4$, 0.6, 0.8, 1.0 and $1.2 \mathrm{mM}$ ) were applied as a foliar spray on one month old seedlings. Salt stress imposed negative impact on growth (Shoot and root length, plant fresh and dry mass), ionic $\left(\mathrm{K}^{+}\right)$and physiological (photosynthetic rate and transpiration rate) attributes in both the studied chilli genotypes except $\mathrm{Na}^{+}$which increased under salinity stress. However, maximum reduction was observed in A-120 as compared to Plahi genotype. In contrast, foliar application of proline under salt stress conditions stimulated shoot and root length, plant fresh and dry mass, photosynthetic rate, transpiration rate and antioxidant enzyme (SOD and CAT) activities were noted under salt stress in both the genotypes. However, maximum increase was observed in Plahi genotype relative to A-120. Moreover, among all proline concentrations, $0.8 \mathrm{mM}$ proved to be the best concentration regarding growth, physiological, ionic and biochemical attributes in both the genotypes.

Keywords: Chilli, salt stress, crop productivity, proline, photosynthesis, antioxidants.
\end{abstract}

\section{INTRODUCTION}

Salinity is one of the most alarming abiotic stress affecting crop productivity and significant crop loss globally. It impedes plant performance by inducing deleterious effects on germination and plant vigor. Moreover, $6 \%$ of total land area and $30 \%$ in irrigated lands are affected by salinity (Fahad et $a l ., 2014)$. This leads to massive loss in terms of productivity and arable land, as most of the economically important particularly horticultural crops are sensitive to salinity. Chilli is an important cash crop due to its high economical and nutritional value of its fruit (Howard et al., 2000). It is generally categorized as salt sensitive crop. Salt stress reduces chilli production (Navarro et al., 2002). Salinity stress cause changes in physiological processes that cause reduction in plant growth and productivity. Salt stress, increased osmotic potential, generates water deficit conditions in the soil (Navarro et al., 2003), ionic toxicity, because of high concentration of toxic ions $\left(\mathrm{Na}^{+}\right.$and $\left.\mathrm{Cl}^{-}\right)$that accumulate within the plant, ionic imbalance due to the accumulation of ions in the plant cells, which cause the deficiency of the others nutrients (Lycoskoufis et al., 2005). Under salinity stress increased level of reactive oxygen species (ROS) in cells causes $\mathrm{K}^{+}$efflux from the cells. Increased ROS concentrations weakens the defense mechanism which leads to oxidative stress. ROS are very destructive to plants at higher concentrations. Under salinity stress ROS increases and can pose a threat to plant cells by causing lipids peroxidation, proteins oxidation, impairment of nucleic acids, inhibit activation of enzymes, activates programmed cell death and ultimately leading to death of the cells (Sharma et al., 2012). There are different approaches used to combat salt stress like conventional breeding, genetic manipulation and foliar application of osmoprotectants. The complexity and polygenic nature of salt tolerance in crops are important factors contributing to the difficulties in breeding salt tolerant crop varieties. Breeding efforts have been hampered by a lack of understanding to salt tolerance mechanisms as well as a lack of field and laboratory screening tests (Zhu, 2000). Genetic screening technique includes diverse plant genetic resources that provides opportunity to develop improved and resistant cultivars with desirable features, that are beneficial for farmers (yield potential and large seed) as well as for breeders (abiotic stress tolerance potential, disease and pest resistance and photosynthesis) (Govindaraj et al., 2015). Proline which is usually considered as an osmoprotection agent is also known to be involved in reducing the oxidative damage by scavenging the free radicals. Proline may also play a role as protein compatible hydrotrope (Ashraf and Foolad, 2007). It supports cytoplasmic acidosis and maintain 
appropriate $\mathrm{NADP}^{+} / \mathrm{NADPH}$ ratios suitable with metabolism. After relief from stress, rapid breakdown of proline occurs that may give sufficient reducing agents that take part in mitochondrial oxidative phosphorylation and produce ATP for retrieval from stress and restoring of stress-induced injuries (Lehmann et al., 2010).

Different scientists reported ameliorative effects of proline in different crops like wheat (Talat et al., 2013), maize (Ali et al., 2007), tobacco (Okuma et al., 2004) and olive (Ahmed et al., 2011). Foliar application of proline is a shotgun approach in minimizing deleterious effects of salinity. Moreover, crop plants show resistance to oxidative damage by inducing high levels of antioxidants, accumulation of certain organic osmolytes and reducing the toxic ions $\left(\mathrm{Na}^{+}\right.$and $\left.\mathrm{Cl}^{-}\right)$. Antioxidant enzymes activity such as superoxide dismutase (SOD), catalase (CAT) and peroxidase (POX) is significantly increased in response to foliar applied proline in tobacco suspension cultures under salinity stress (Hoque et al., 2007; Hayat et al., 2012).

Roy et al. (1993) proline, applied exogenously at a low concentration, ameliorated the adverse effects of salinity in rice. When added to the culture medium at low concentrations proline effectively alleviated salinity induced decline in fresh weight and also reduced peroxidative damage to the lipid membranes in ground nut. Exogenous application of proline to culture medium subjected to salinity stress resulted in an increase in dry weight and also increased the free proline content in callus cells of alfalfa (Hayat et al., 2012).

Salt stress reduces chilli plant growth, development and production. (Azuma et al., 2010). Exogenous application of proline can alleviate salt stress and enhances the productivity as a short term and economical approach. Ashraf and Foolad (2007) reported that foliar application of proline is a shotgun strategy to alleviate salt stress and enhances the crop growth and its yield. Thus, by assuming foliar application of proline as a short term and viable approach and considering chilli as an important horticultural crop, an experiment was planned to apply proline on chilli crop grown under saline conditions to uplift its growth and salt tolerance potential and also to identify the best suitable concentration that gives the better response against the salinity stress.

\section{MATERIALS AND METHODS}

Pot experiment was conducted in the lath house of Institute of Horticultural Sciences, University of Agriculture Faisalabad, Pakistan. Seeds were disinfected by rinsing in ethanol $(80 \%)$ for $5 \mathrm{~min}$ and washed continuously with deionized water. Seeds were then cleaned with sodium hypochlorite (30\%) and Tween-20 (1 drop) for $15 \mathrm{~min}$. Seeds were washed continuously with deionized water (Quintal et al., 2014). The surface sterilized seeds of two chilli genotypes namely; Plahi and A-120 were sown in pots having fine sand as growth medium. To evade the osmotic shock, $\mathrm{NaCl}$ concentrations were adjusted by gradually increasing $15 \mathrm{mM}$ every $2^{\text {nd }}$ days until $30 \mathrm{mM}$ concentration while $20 \mathrm{mM}$ was added after $2^{\text {nd }}$ day to achieve $50 \mathrm{mM}$ salt concentration. Each pot (four plants) was considered as one replicate and there were four pots per treatment. The desired salinity levels were maintained throughout the experiment by measuring the EC of the growing medium (sand) with the help of EC meter. Any increase or decrease in required salinity level was adjusted with the help of buffer solution. Seedlings were irrigated with half strength Hoagland nutrient solution (Hoagland and Arnon, 1950). After one week of last salt stress application, various levels of proline $(0.4,0.6,0.8,1.0$ and $1.2 \mathrm{mM})$ were applied as foliar spray on chilli seedlings. Moreover, surfactant Tween-20@ $0.1 \%$ was added to ensure the maximum absorption of proline. After two weeks of proline application, plants were harvested for the measurement of plant growth, ionic and biochemical attributes.

Collected plants were cleaned with deionized water and kept carefully on tissue paper and then salinity effects were studied by measuring shoot and root lengths, fresh and dry weights of studied chilli genotypes. After that plant material was dried at $80^{\circ} \mathrm{C}$ for 48 hours to measure plant dry weights. Thereafter, they were weighed and finely grounded for the measurement of $\mathrm{Na}^{+}$and $\mathrm{K}^{+}$by the method described by Wolf (1990). For the measurement of gas exchange parameters such as photosynthetic rate $(P n)$ and transpiration rate $(E)$, three young, healthy and fully developed leaves per plant were selected. Selected leaves were used to place in the chamber of portable apparatus termed as InfraRed Gas Analyzer (IRGA) (Analytical Development Company, Hoddesdon, England). All the readings of above mentioned physiological attributes were taken at day time from 10.00 to 12.00 a.m. with leaf temperature of 28.4 to $32.4^{\circ} \mathrm{C}$, ambient temperature 22.4 to $27.9^{\circ} \mathrm{C}$ and $352 \mu \mathrm{mol} \mathrm{mol}{ }^{-1}$ ambient $\mathrm{CO}_{2}$ concentrations (Zekri, 1991). Frozen leaf samples $(0.5 \mathrm{~g})$ were homogenized in $5 \mathrm{~mL}$ phosphate buffer $(50 \mathrm{mM})(\mathrm{pH} 7.8$ for SOD and $\mathrm{pH} 7$ for CAT). Then centrifuged these materials at $15,000 \mathrm{rpm}$ for $20 \mathrm{~min}$ at $4^{\circ} \mathrm{C}$. The supernatant was used to measure the activity of antioxidant enzymes. The SOD activity was analyzed according to the method of Giannopolitis and Ries (1977) by calculating its potential to hinder the photo reduction of nitroblue tetrazolium (NBT). Catalase (CAT) activity was measured by the protocol of Chance and Maehly (1955). Malondialdehyde (MDA) contents were estimated by the method of Heath and Packer (1968).

The experiment was laid out in a completely randomized design (CRD) with factorial arrangements and treatment means were grouped on the basis of honestly significant difference (HSD, Tukey test) at 0.05 level of probability by using the statistical software, Statistix 8.1 (Analytical Software, 2005). 


\section{RESULTS}

This experiment was carried out to optimize concentration of foliaged applied proline to improve salt tolerance in investigated chilli genotypes. Growth attributes such as shoot and root length, fresh and dry weights were significantly $(p<0.05)$ influenced by the foliar application of different levels of proline under salt stress condition (Table 1). All growth attributes decreased under salt stress with no proline application. Data indicated that among all the proline treatments under salt stress, significant increase in seedling shoot length, seedling root length, seedling fresh weight and dry weight was noted at $0.8 \mathrm{mM}$ proline concentration. Exogenous proline application had significant impact on shoot length and root length in both the genotypes but maximum increase $(10.6 \mathrm{~cm})$ in shoot length was observed in Plahi and minimum increase $(9.53 \mathrm{~cm})$ was noted in A-120, respectively. Foliar application of proline also improved the seedling fresh weight and dry weight but this increasing effect of exogenous proline application was more prominent at 0.8 $m M$ proline treatment under salt stressed condition in both the genotypes with respect to control.

Salt stress had significant effect on leaf $\mathrm{Na}^{+}$concentration in Plahi and A-120 genotypes. Leaf $\mathrm{Na}^{+}$concentration increased under saline condition but reduced with the foliar spray of proline. Maximum reduction $\left(0.27 \mathrm{mg} \mathrm{g}{ }^{-1}\right.$ D.W.) in $\mathrm{Na}^{+}$ concentration was recorded at $0.8 \mathrm{mM}$ proline concentration in leaves of Plahi with respect to A-120 ( $0.46 \mathrm{mg} \mathrm{g}^{-1}$ D.W. $)$ as shown in Figure 1A. Salt stress significantly decreased the leaf potassium $\left(\mathrm{K}^{+}\right)$concentration. However, foliar applied proline under salt stress enhanced the leaf $\mathrm{K}^{+}$concentration in both the genotypes. However, maximum increment (15.9 mg $\mathrm{g}^{-1}$ D.W.) was recorded in Plahi genotype (Fig. 1B).

Salt stress caused a significant reduction in photosynthetic rate $(P n)$ of both chilli genotypes (Fig. 1C). Exogenous application of all levels of proline significantly enhanced the photosynthetic rate of both genotypes under saline condition with respect to the saline control without foliar spray of proline. Proline application proved to be more effective in boosting the photosynthetic rate in both the genotypes with respect to saline without proline foliar spray. However, higher photosynthetic rate was observed in Plahi $\left(16 \mu \mathrm{mol} \mathrm{CO} \mathrm{Cm}^{-2}\right.$ $\left.\mathrm{s}^{-1}\right)$ while lowest was recorded in A-120 (13.1 $\mu \mathrm{mol} \mathrm{CO} \mathrm{Cm}^{-2}$ $\mathrm{s}^{-1}$ ) genotype.

Transpiration rate $(E)$ of both studied genotypes was significantly $(p<0.05)$ suppressed due to salt stress (Fig. 1D). However, proline induced enhancement in transpiration rate which was minimum in A-120 and maximum in Plahi under stressed conditions as compare to saline control. Data related to the transpiration rate indicated that among all the proline treatments, $0.8 \mathrm{mM}$ remarkably mitigated the adverse effect of salt stress by showing the maximum increase in transpiration rate by 9.85 and $6.88 \mathrm{mmol} \mathrm{H}_{2} \mathrm{O} \mathrm{m}^{-2} \mathrm{~s}^{-1}$ in Plahi and A-120, respectively.

All proline levels significantly increased SOD activity in both the genotypes (Fig. 2A). Data regarding SOD activity exhibited that proline alleviated the adverse effects of salt stress by enhancing the maximum SOD activity in Plahi $(57.5 \%)$ and A-120 (50.7\%) with respect to saline control. In both genotypes, there was a significant difference $(p<0.05)$ in MDA activity between saline control and among all proline levels (Fig. 2B). Salt stress enhanced MDA contents.

Table 1. Effect of proline on growth attributes of A-120 (S) and Plahi (T) chilli genotypes under salt stress.

\begin{tabular}{lcccccc}
\hline Genotypes & Saline $(\boldsymbol{m M})$ & Proline $(\boldsymbol{m M})$ & Shoot length $(\mathbf{c m})$ & Root length $(\mathbf{c m})$ & Fresh weight $(\mathbf{g})$ & Dry weight $(\mathbf{g})$ \\
\hline A-120 & 0 & 0 & $11.10 \pm 0.06 \mathrm{a}$ & $6.13 \pm 0.06 \mathrm{a}$ & $1.16 \pm 0.01 \mathrm{ab}$ & $0.17 \pm 0.01 \mathrm{a}$ \\
& 50 & 0 & $4.05 \pm 0.17 \mathrm{j}$ & $2.23 \pm 0.05 \mathrm{i}$ & $0.25 \pm 0.01 \mathrm{k}$ & $0.02 \pm 0.03 \mathrm{i}$ \\
& 50 & 0.4 & $5.90 \pm 0.16 \mathrm{~h}$ & $3.62 \pm 0.03 \mathrm{fg}$ & $0.35 \pm 0.03 \mathrm{j}$ & $0.04 \pm 0.02 \mathrm{~h}$ \\
& 50 & 0.6 & $7.40 \pm 0.11 \mathrm{f}$ & $4.65 \pm 0.04 \mathrm{~d}$ & $0.69 \pm 0.04 \mathrm{f}$ & $0.06 \pm 0.01 \mathrm{ef}$ \\
& 50 & 0.8 & $9.53 \pm 0.04 \mathrm{c}$ & $5.41 \pm 0.03 \mathrm{c}$ & $0.92 \pm 0.01 \mathrm{c}$ & $0.09 \pm 0.04 \mathrm{c}$ \\
& 50 & 1.0 & $6.31 \pm 0.03 \mathrm{~g}$ & $4.10 \pm 0.05 \mathrm{e}$ & $0.54 \pm 0.05 \mathrm{~h}$ & $0.05 \pm 0.03 \mathrm{~g}$ \\
Plahi & 50 & 1.2 & $5.12 \pm 0.15 \mathrm{i}$ & $3.21 \pm 0.06 \mathrm{~h}$ & $0.46 \pm 0.02 \mathrm{i}$ & $0.05 \pm 0.02 \mathrm{~h}$ \\
& 0 & 0 & $11.60 \pm 0.14 \mathrm{a}$ & $6.23 \pm 0.03 \mathrm{a}$ & $1.26 \pm 0.02 \mathrm{a}$ & $0.18 \pm 0.04 \mathrm{a}$ \\
& 50 & 0 & $6.33 \pm 0.14 \mathrm{~g}$ & $3.33 \pm 0.05 \mathrm{~g}$ & $0.62 \pm 0.01 \mathrm{~g}$ & $0.06 \pm 0.03 \mathrm{f}$ \\
& 50 & 0.4 & $8.05 \pm 0.43 \mathrm{e}$ & $4.00 \pm 0.03 \mathrm{e}$ & $0.76 \pm 0.05 \mathrm{e}$ & $0.08 \pm 0.02 \mathrm{e}$ \\
& 50 & 0.6 & $9.08 \pm 0.16 \mathrm{~d}$ & $5.10 \pm 0.03 \mathrm{~d}$ & $0.85 \pm 0.09 \mathrm{~d}$ & $0.09 \pm 0.01 \mathrm{c}$ \\
& 50 & 0.8 & $10.80 \pm 0.06 \mathrm{~b}$ & $6.0 \pm 0.06 \mathrm{~b}$ & $1.02 \pm 0.02 \mathrm{~b}$ & $0.12 \pm 0.05 \mathrm{~b}$ \\
& 50 & 1.0 & $7.55 \pm 0.04 \mathrm{f}$ & $4.53 \pm 0.04 \mathrm{~d}$ & $0.93 \pm 0.03 \mathrm{c}$ & $0.08 \pm 0.02 \mathrm{~d}$ \\
& 50 & 1.2 & $6.68 \pm 0.15 \mathrm{~g}$ & $3.75 \pm 0.08 \mathrm{f}$ & $0.69 \pm 0.04 \mathrm{f}$ & $0.07 \pm 0.01 \mathrm{ef}$
\end{tabular}

Each value in the above figures is the mean of 4 replicates and \pm standard error of means; Means sharing similar letter are statistically non-significant. HSD (Tukey Test) for genotypes and treatments were significant at $p<0.05$. 
However, MDA contents decreased with foliar spray of proline. Nevertheless, proline @ $0.8 m M$ concentration proved to be the best in decreasing MDA contents in leaves of both genotypes.

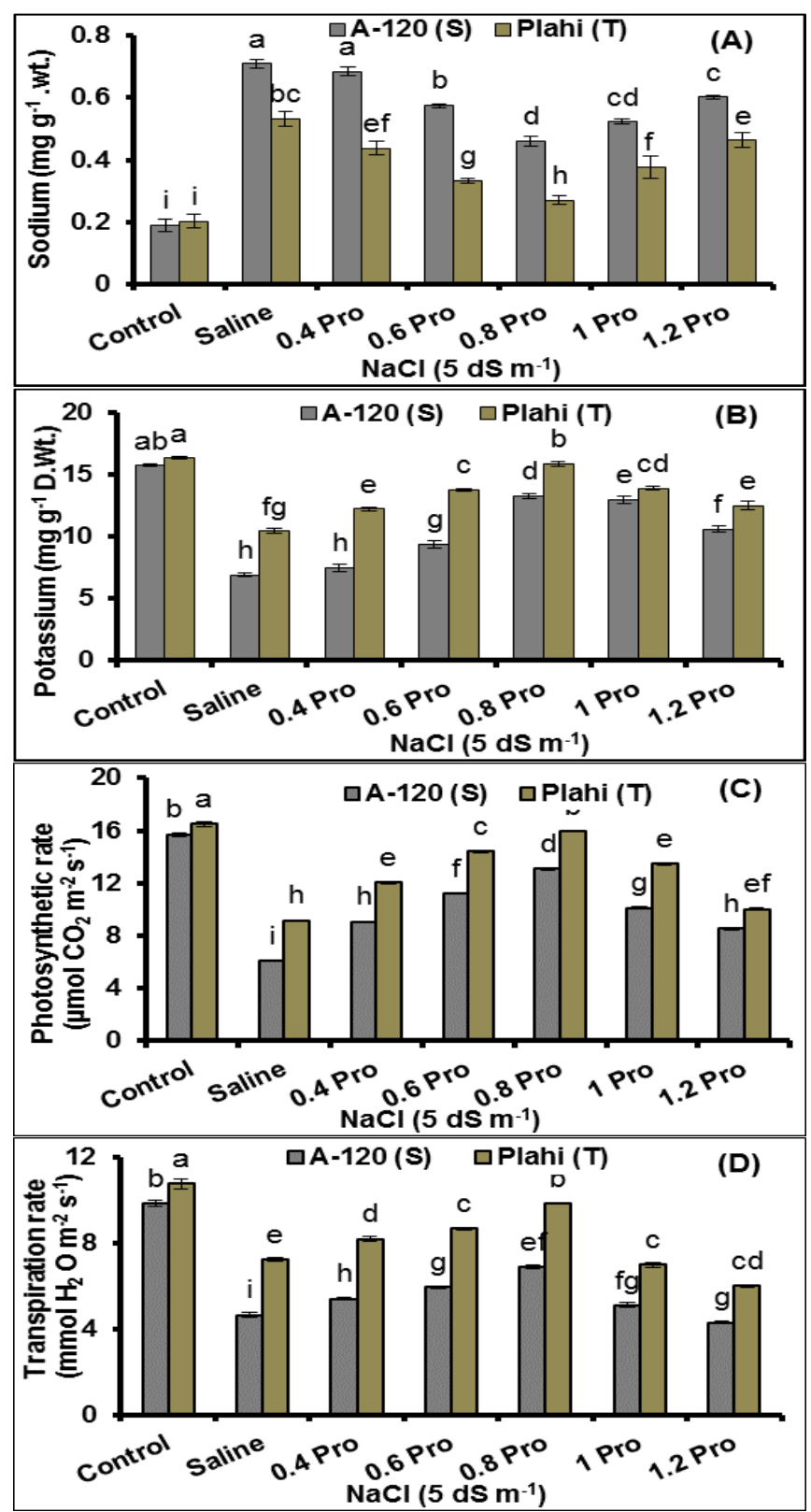

Each value in above figures is the mean of four replicates and vertical bars give standard errors (SE) of the means. HSD (Tukey Test) for genotypes and treatments were significant at $\mathrm{p} \leq 0.05$. A (Sodium), B (Potassium), C (Photosynthesis), D (Transpiration rate).

Figure 1.Effect of proline (Pro) on leaf sodium $\left(\mathrm{Na}^{+}\right)$, potassium $\left(\mathrm{K}^{+}\right)$concentration, photosynthetic rate $(P n)$ and transpiration rate $(E)$ in Plahi and A-120 Chilli genotypes under salt stress.

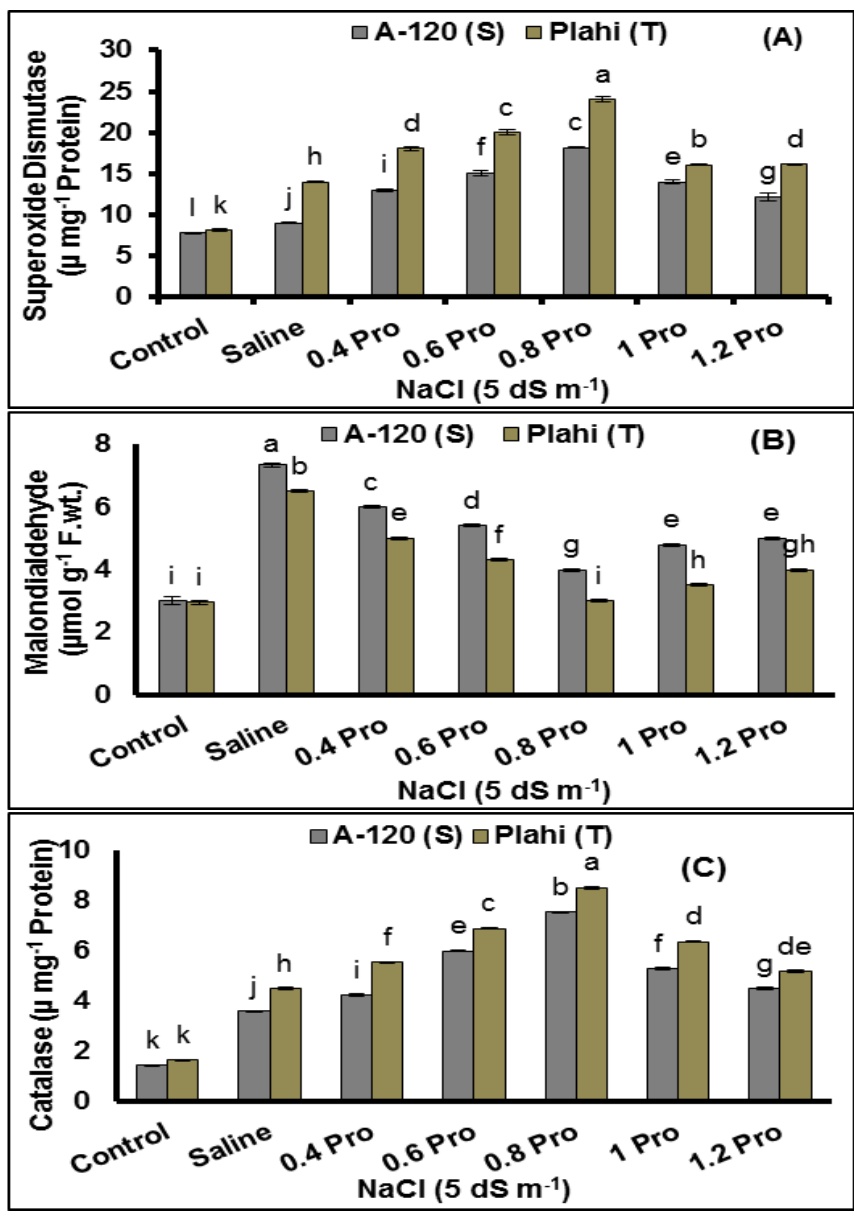

Each value in above figures is the mean of four replicates and vertical bars give standard errors (SE) of the means. HSD (Tukey Test) for genotypes and treatments were significant at $p \leq 0.05$. A (Superoxide dismutase), B (Malondialdehyde), C (Catalase).

Figure 2. Effect of proline (Pro) on Super oxide dismutase (SOD), malondialdehyde (MDA) and catalase (CAT) in Plahi and A-120 chilli under salt stress.

The results showed that CAT activity significantly increased in both the tested genotypes in response to spray of all the proline levels under salt stress. Data regarding CAT activity showed that proline at $0.8 \mathrm{mM}$ concentration improved the adverse effect of salt stress by exhibiting the maximum percentage increase in CAT activity by 8.5 and $7.6 \mu \mathrm{mg}^{-1}$ protein in Plahi and A-120, respectively with respect to control (Fig. 2 C).

\section{DISCUSSION}

There are different approaches used to alleviate the harmful effects of salt stress. It includes foliar spray of osmoprotectants such as proline, betaines, amino acids and sugar trehalose (Ashraf and Foolad, 2007). Among the osmoprotectants, proline (Pro) is one of the more efficient 
osmolyte used for improving the salt tolerance in crops. In current study, exogenously applied proline improved the salt tolerance in both chilli genotypes. Both genotypes responded differentially to various levels of proline under salt stress (Table 1). It has also been proposed that proline application can work as selection standard for salinity tolerance in most of the crop plants including horticultural crops (Ahmad et al., 2009). Foliage applied proline was found to be more effective in mitigating the adverse effects of salinity in both the studied genotypes; Plahi and A-120 but maximum increase was observed in Plahi. Proline influenced seedlings, shoot and root length, seedlings fresh and dry weights in both genotypes (Table 1).

Proline application may elevate the uptake of beneficial macro-nutrients to maintain the osmotic balance by reducing the concentration of toxic ions $\left(\mathrm{Na}^{+}\right.$and $\left.\mathrm{Cl}^{-}\right)$which assist normal growth and development of crops (Hoque et al., 2007; Ashraf and Foolad, 2007; Nawaz et al., 2010). Foliar application of proline decreased the leaf $\mathrm{Na}^{+}$concentration in both the genotypes and maintains the improved growth of plant with respect to control (Fig. 1A). Proline excludes maximum $\mathrm{Na}^{+}$from the leaves of both genotypes and maintains the plants osmotic potential as proline play vital role in reinforcing the osmotic adjustment (Ahmed et al., 2011). Proline application also increased the $\mathrm{K}^{+}$concentration in leaves of both genotypes (Fig. 1B). $\mathrm{K}^{+}$efflux was significantly reduced by the application of proline and ionic homeostasis was maintained by enhancing the $\mathrm{H}^{+}$ATPase activity (Cuin and Shabala, 2007). Proline application increased the leaf $\mathrm{K}^{+}$concentration under salt stress and improved the growth of chilli plants (Fig. 1B).

Foliage applied proline significantly increased the photosynthetic (Fig. 1C) and transpiration rate (Fig. 1D) in both the chilli genotypes. Under salt stress, photosynthetic and transpiration rate reduced due to accumulation of higher concentrations of $\mathrm{Na}^{+}$and $\mathrm{Cl}^{-}$in chloroplasts. However, foliar applied proline under salt stress reduced the toxic ions $\left(\mathrm{Na}^{+}\right.$ and $\mathrm{Cl}^{-}$) from leaves by osmotic adjustment. Proline also maintains carbon utilization and water loss through transpiration under salt stress and increased the photosynthetic activity (Raven, 2002). ROS such as superoxide radical was scavenged properly by enhancing SOD activity and thus, reduced cell membranes and oxidative stress damages. Oxidative stress increased in cells under salt stress. If ROS such as superoxide radical is not scavenged, it interrupts functioning of vital biomolecules (Mittler, 2002). Proline application increased the SOD activity under salt stress in both chilli genotypes (Fig. 2A). There was a negative correlation between MDA contents and SOD activity. Maximum SOD activity was found at $0.8 \mathrm{mM}$ proline and decreased MDA contents were observed in both the tested chilli genotypes as earlier reported by Azuma et al. (2010) and Al-aghabary et al. (2004). Accumulation of proline in the cytosol under salt stress environment might be enough for osmotic adjustment. It has been reported that proline activate other defense mechanisms in response to salt stress, such as the activation of antioxidant enzymes and protect protein by forming strong $\mathrm{H}$-bonded water around protein structures and decreased the MDA (Chutipaijit et al., 2009). Application of foliar proline significantly increased CAT activity in chilli genotypes as reported by Duan et al. (2008). Exogenously applied proline conferred tolerance in cultured tobacco cells by increasing the activities of SOD and CAT and also decreased the lipid peroxidation rate by reducing MDA contents as in present study. Proline application improved salt tolerance in tobacco plants by activating the antioxidant enzymes involved in the defense system (Hoque et al. 2008) as observed in current experiment. Candan and Tarhan (2003) and Martinez et al. (2001) had similar findings and also reported that the increase in activity of antioxidant enzymes (SOD and CAT) and decrease in oxidative stress damages were closely interrelated.

Conclusion: Salt stress negatively affected the studied growth, ionic $\left(\mathrm{K}^{+}\right)$and physiological attributes to both chilli genotypes. Moreover, Plahi respond more efficiently to the applied proline concentrations than A-120. Thus, Plahi proved as salt tolerant genotype and A-120 as salt sensitive genotype. Since results show positive impact of foliar applied proline levels, but $0.8 \mathrm{mM}$ was found to be more effective in alleviating salinity stress in chilli genotypes. Thus, screened salt tolerant chilli genotype (Plahi) can successfully be recommended for its cultivation in saline zones and proline @ $0.8 \mathrm{mM}$ may be used as a potential osmoprotectant to counter the harmful effects of salt stress. So a resistant genotype along with supplementary effects of proline might appear a promising strategy to grow chilli on salt affected area of the country. Further field application of this approach is recommended. Additionally, selected salt tolerant genotype can also be employed in various breeding and molecular programs for salt stress tolerance induction.

Acknowledgement: The authors highly acknowledge Higher Education Commission of Pakistan for its financial support and Institute of Horticultural Sciences, University of Agriculture, Faisalabad, Pakistan for research assistance.

\section{REFERENCES}

Ahmad, S., R. Ahmad, M.Y. Ashraf, M. Ashraf and E.A. Waraich. 2009. Sunflower (Halianthus annuus L.) to drought stress at germination and seedling stages. Pak. J. Bot. 41:647-654.

Ahmed, B.C., S. Magdich, B. Rouina, S. Sensoy M. Boukhris and F.B. Abdullah. 2011. Exogenous proline effects on water relations and ions contents in leaves and roots of young olive. Am. Acids 40:565-573. 
Al-Aghabary, K., Z. Zhu and Q. Shi. 2004. Influence of silicon supply on chlorophyll content, chlorophyll fluorescence and anti-oxidative enzyme activities in tomato plants under salt stress. J. Plant Nutr. 27:21012115.

Ali, Q., M. Ashraf and H.U.R. Athar. 2007. Exogenously applied proline at different growth stages enhances growth of two maize cultivars grown under water deficit conditions. Pak. J. Bot. 39:1133-1144.

Analytical Software. 2005. Statistix 8.1 User's Manual. Tallahassee (FL): Analytical Software.

Ashraf, M. and M.R. Foolad. 2007. Roles of glycinebetaine and proline in improving plant abiotic stress resistance. Environ. Exp. Bot. 59:206-216.

Azuma, R., N. Ito, N. Nakayama, R. Suwa, N.T. Nguyen, J.A. Larrinaga-Mayoral, M. Esaka, H. Fujiyama and H. Saneoka. 2010. Fruits are more sensitive to salinity than leaves and stems in pepper plants (Capsicum annuum L.). Sci. Hortic. 125:171-178.

Candan, N. and L. Tarhan. 2003. The correlation between antioxidant enzyme activities and lipid peroxidation levels in Mentha pulegium organs grown in $\mathrm{Ca}^{2+}, \mathrm{Mg}^{2+}$, $\mathrm{Cu}^{2+}, \mathrm{Zn}^{2+}$ and $\mathrm{Mn}^{2+}$ stress conditions. Plant Sci. 163:769-779.

Chance, M. and A.C. Maehly. 1955. Assay of catalases and peroxidases. Methods Enzy. 2:764-817.

Chutipaijit, S., C. Suriyan and S. Kanokporn. 2009. Differential accumulations of proline and flavonoids in indica rice varieties against salinity. Pak. J. Bot. 41:24972506.

Cuin, T.A. and S. Shabala. 2007. Potassium efflux channels mediate Arabidopsis root responses to reactive oxygen species and the mitigating effect of compatible solutes. Plant Cell Environ. 7:875-885.

Duan, J.J., J. Li, S.R. Guo and Y.Y. Kang. 2008. Exogenous spermidine affects polyamine metabolism in salinitystressed Cucumis sativus roots and enhances short-term salinity tolerance. J. Plant Physiol. 165:1620-1635.

Fahad, S., S. Hussain, A. Matloob, F.A. Khan, A. Khaliq, S. Saud, S. Hassan, D. Shan, F. Khan, N. Ullah, M. Faiq, M.R. Khan, A.K. Tareen, A. Khan, A. Ullah, N. Ullah, and J. Huang. 2014. Phytohormones and plant responses to salinity stress: a review. Plant Growth Reg. 75:391404.

Giannopolitis, C.N. and S.K. Ries. 1977. Superoxide dismutase. I. Occurrence in higher plants. Plant Physiol. 59:309-314.

Govindaraj, M., M. Vetriventhan and M. Srinivasan. 2015. Importance of genetic diversity assessment in crop plants and its recent advances: an overview of its analytical perspectives. Gene. Res. Int. p:14.

Hayat, S., Q. Hayat, M.N. Alyemeni, A.S. Wani, J. Pichtel and A. Ahmad. 2012. Role of proline under changing environments: a review. Plant Signal. Behav. 7:14561466.

Heath, R.L. and L. Packer. 1968. Photoperoxidation in isolated chloroplasts. I. Kinetics and stoichiometry of fatty acid peroxidation. Arch. Biochem. Biophys. 125:189-198.

Hoagland, D.R. and D.S. Arnon. 1950. The water culture method for growing plants without soil. Calif. Agric. Exp. Stat. Circ. 374:1-32.

Hoque, M.A., M.N. Banu, E. Okuma, K. Amako, Y. Nakamura and Y. Shimoishi. 2007. Exogenous proline and glycinebetaine increase $\mathrm{NaCl}$-induced ascorbateglutathione cycle enzyme activities, and proline improves salt tolerance more than glycinebetaine in tobacco Bright Yellow-2 suspension-cultured cells. J. Plant Physiol. 164:1457-68.

Hoque, M.A., M.N. Banu, Y. Nakamura, Y. Shimoishi and Y. Murata. 2008. Proline and glycinebetaine enhance reduce $\mathrm{NaCl}$-induced damage in cultured tobacco cells. J. Plant Physiol. 165:813-824.

Howard, L.R., S.T. Talcott, C.H. Brenes and B. Villalon. 2000. Changes in phytochemical and antioxidant activity of selected pepper cultivars (Capsicum species) as influenced by maturity. J. Agric. Food Chem. 48:17131720.

Lehmann, S., D. Funck, L. Szabados and D. Rentsch. 2010. Proline metabolism and transport in plant development. Amino Acids 39:949-962.

Lycoskoufis, L.H., D. Savvas and G. Mavrogianopoulos. 2005. Growth, gas exchange and nutrient status in pepper (Capsicum annum L.) grown in re-circulating nutrient solution as affected by salinity imposed to half of the root system. Sci. Hortic. 106:147-161.

Martinez, C.A., M.E. Loureiro, M.A. Oliva and M. Maestri. 2001. Differential responses of superoxide dismutase in freezing resistant Solanum tuberosum subjected to oxidative and water stress. Plant Sci. 160:505-515.

Mittler, R. 2002. Oxidative stress, antioxidant and stress tolerance. Trends Plant Sci. 7:405-410.

Navarro, J.M., C. Garrido, M. Carvajal and V. Martinez. 2002. Yield and fruit quality of pepper plants under sulphate and chloride salinity. J. Hort. Sci. Biotech. 77:52-57.

Navarro, J.M., C. Garrido, V. Martínez and M. Carvajal. 2003. Water relations and xylem transport of nutrients in pepper plants grown under two different salts stress regimes. Plant Growth Regul. 41:237-245.

Nawaz, K., A.I. Talat, K. Hussain and A. Majeed. 2010. Induction of salt tolerance in two cultivars of sorghum (Sorghum bicolor L.) by exogenous application of proline at seedling stage. World App. Sci. J. 10:93-99.

Okuma, E., Y. Murakami, Y. Shimoishi, M. Tada and Y. Murata. 2004. Effects of exogenous application of proline and betaine on the growth of tobacco cultured 
cells under saline conditions. Soil Sci. Plant Nutr. 50:1301-1305.

Quintal, B.E., A.V. Buendia, A.K. Gonzalez, M.C. Pech, D.O. Camacho, I.E. Machado, I. Pottosin and M.M. Estevez1. 2014. Mechanisms of salt tolerance in habanero pepper plants (Capsicum chinense Jacq.): Proline accumulation, ions dynamics and sodium root-shoot partition and compartmentation. Front. Plant Sci. 5:605.

Raven, J.A. 2002. Selection pressures on stomatal evolution. New Phytol. 153:371-386.

Roy, D., N. Basu, A. Bhunia and S. Banerjee. 1993. Counteraction of exogenous L-proline with $\mathrm{NaCl}$ in saltsensitive cultivar of rice. Biol. Plant. 35:69-72.

Sharma, C., N. Singh and K. Pal. 2012. The effect of salt stress on biochemicals of chilli at seedling level. Int. J. Pharma. Prof. Res. 3:665-670.
Talat, A., K. Nawaz, K. Hussian, K. Hayat Bhatti, E.H. Siddiqi, A. Khalid, S. Anwer and M.U. Sharif. 2013. Foliar application of proline for salt tolerance of two wheat (Triticum aestivum L.) cultivars. World App. Sci. J. 22:547-554.

Wolf, B. 1990. A comparative system of leaf analysis and its use for diagnosing nutrient status. Comm. Soil Sci. Plant Anal. 13:1053-1059.

Zekri, M. 1991. Effects of $\mathrm{NaCl}$ on growth and physiology of sour orange and Cleopatra mandarin seedlings. Sci. Hortic. 47:305-315.

Zhu, J.K. 2000. Genetic analysis of plant salt tolerance using Arabidopsis. Plant Physiol. 124:941-948. 